\title{
Performance of Ti6Al4V fabricated by electron beam and laser hybrid preheating and selective melting strategy
}

\author{
Mo-han Hao, * Lei Zhang, Bin Zhou, Hong-xin Li, Ming-zhi Li, Feng Lin \\ Biomanufacturing and Rapid Forming Technology Key Laboratory of Beijing, Department of Mechanical Engineering, Tsinghua University, \\ Beijing 100084, China
}

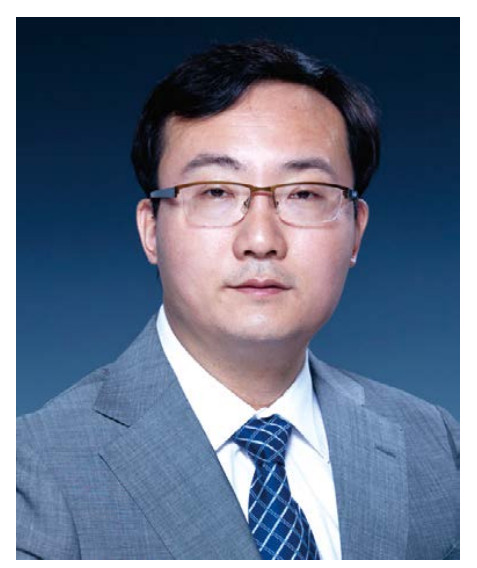

\section{*Lei Zhang}

Male, born in 1977, Ph. D., Associate Professor. His research mainly focuses on additive manufacturing, bio fabrication, and forging technology. To date, he has published about 30 papers in SCl-indexed journals.

E-mail: stoneszhang@tsinghua.edu.cn

\begin{abstract}
Electron beam selective melting (EBM) and selective laser melting (SLM) are regarded as significant manufacturing processes for near-net-shaped Ti6Al4V components. Generally, in the conventional EBM process, preheating is necessitated to avoid "smoke" caused by the charging of electrons. In the conventional SLM process, laser as an energy source without the risk of "smoke" can be employed to melt metal powder at low temperatures. However, because of the low absorption rate of laser, the powder bed temperature cannot reach a high level. It is difficult to obtain as-built TiAl4V with favorable comprehensive properties via conventional EBM or SLM. Hence, two types of electron beam and laser hybrid preheating (EB-LHP) combined with selective melting strategies are proposed. Using laser to preheat powder allows EBM to be performed at a low powder bed temperature (EBM-LT), whereas using an electron beam to preheat powder allows SLM to be performed at a high powder bed temperature (SLM-HT). Ti6Al4V samples are fabricated using two different manufacturing strategies (i.e., EBM-LT and SLM-HT) and two conventional processes, i.e., EBM at a high powder bed temperature (EBM-HT) and SLM at a low powder bed temperature (SLM-LT). The temperature-dependent surface quality, microstructure, density, and mechanical properties of the as-built Ti6Al4V samples are characterized and compared. Results show that EBM-LT Ti6AI4V exhibits a higher ultimate tensile strength $(981 \pm 43 \mathrm{MPa})$ and a lower elongation $(12.2 \% \pm 2.3 \%)$ than EBM-HT Ti6Al4V owing to the presence of $\alpha^{\prime}$ martensite. The SLM-HT Ti6Al4V possesses the highest ultimate tensile strength $(1,059 \pm 62 \mathrm{MPa})$ and an elongation $(14.8 \% \pm 4.0 \%)$ comparable to that of the EBM-HT Ti6Al4V (16.6\% $\pm 1.2 \%)$.
\end{abstract}

Key words: Ti6AI4V; electron beam selective melting; selective laser melting; hybrid preheating

CLC numbers: TG146.23; Document code: A; Article ID: 1672-6421(2021)04-351-09

\section{Introduction}

Electron beam selective melting (EBM) and selective laser melting (SLM) are two promising powder-bed based additive manufacturing (AM) technologies; their operating principles differ significantly. In EBM, the substrate and metal powder are firstly preheated by a defocused electron beam; subsequently, slightly sintered powder is selectively melted by a focused electron beam. The preheating temperature is set based on the powder material. Ti6Al4V powder can be processed at $600-800{ }^{\circ} \mathrm{C}^{[1,2]}$, whereas TiAl alloys require temperatures exceeding $1,000{ }^{\circ} \mathrm{C}^{[3]}$. The elevated powder bed temperature is primarily aimed at preventing "smoke" ${ }^{[4]}$ induced by charge accumulation, which is a unique undesirable phenomenon in the EBM process that typically results in process termination. In addition, the elevated temperature reduces residual stresses as well as avoids distortions and warpages. Nevertheless, laser as an energy source is used in SLM to melt metal powder. Because the energy absorption rate of laser is much lower 
than that of electron beam, SLM is typically performed at low temperatures $\left(100-400{ }^{\circ} \mathrm{C}{ }^{[5]}\right)$. Although many problems remain in EBM and SLM processes, their capacities for fabricating near-net shape, complex-shaped, and highperformance components have attracted increasing attention.

Ti6A14V, as an $\alpha+\beta$ dual-phase titanium alloy, is widely used in the aerospace, marine, and biomedical industries owing to its high specific strength, excellent corrosion resistance, and favorable biocompatibility ${ }^{[6]}$. Owing to the differences between EBM and SLM in terms of energy source and preheating temperature, EBM- and SLM-manufactured Ti6A14V components exhibit different advantages and disadvantages in terms of surface quality, residual stress, microstructure, and mechanical properties. Liu and Shin ${ }^{[7]}$ reported surface roughness ranges of 5-40 $\mu \mathrm{m}$ and 25-131 $\mu \mathrm{m}$ for Ti6Al4V samples fabricated by SLM and EBM, respectively. Vayssette et al. ${ }^{[8]}$ reported that the residual stress in SLM Ti6Al4V varied from 100 to $500 \mathrm{MPa}$, while that in EBM Ti6Al4V was extremely low. Rafi et al. ${ }^{[1]}$ compared Ti6Al4V parts fabricated by EBM and SLM and found that the surface of SLM Ti6Al4V was smoother than that of EBM Ti6Al4V owing to thinner layers and finer powder particles of SLM. It was discovered that the microstructure of SLM Ti6Al4V comprised acicular $\alpha^{\prime}$ martensite, resulting in high strength and low ductility, whereas the microstructure of EBM Ti6Al4V was composed of an $\alpha+\beta$ dual-phase, resulting in low strength and high ductility. Zhao et al. ${ }^{[2]}$ compared SLM and EBM processes and obtained a result similar to that mentioned above regarding the microstructures and tensile properties of SLM and EBM Ti6A14V. Owing to the aforementioned performance deficiencies of EBM- and SLM-produced Ti6Al4V, a strength-ductility tradeoff ${ }^{[9]}$ based on application requirements is inevitable.

Significant efforts have been made to comprehensively improve the properties of AM-manufactured Ti6Al4V. Some researchers attempted to customize the microstructure to improve the ductility of SLM-built Ti6AL4V by optimizing the process parameters. Liu et al. ${ }^{[10]}$ successfully manufactured strong and ductile SLM Ti6Al4V by adjusting the scan velocity and laser power; they attributed the favorable results to the process-induced densification effect and the high fraction of the $\alpha$ phase. $\mathrm{Xu}$ et al. ${ }^{[11]}$ achieved in situ martensite decomposition during the SLM of Ti6Al4V by altering the laser powder, scan velocity, line offset, layer thickness, and area ratio of the support structure to the desired component. Three types of microstructures, i.e., fully $\alpha^{\prime}, \alpha^{\prime}+(\alpha+\beta)$, and $(\alpha+\beta)$ were observed, and the $(\alpha+\beta)$ microstructure exhibited the best ultimate tensile strength (UTS, 1,260 $\pm 30 \mathrm{MPa}$ ) and elongation to failure $(>8 \%)$. Nevertheless, the relatively narrow process window for optimal properties and high residual stress caused by the rapid cooling rate $\left(10^{3}-10^{8} \mathrm{~K} \cdot \mathrm{s}^{-1}{ }^{[12]}\right)$ in conventional SLM remain to be addressed. Post-processing treatments such as hot isostatic pressing (HIP), stress relieving, and aging are the mainstream approaches for reducing defects, releasing residual stress, and increasing ductility. Liu et al. ${ }^{[13]}$ investigated the effects of HIP on the microstructure and mechanical properties of EBM Ti6Al4V and discovered that $\mathrm{HIP}$ at $920{ }^{\circ} \mathrm{C}$ for $2 \mathrm{~h}$ increased the ductility from $11.1 \% \pm 4.3 \%$ to $18.8 \% \pm 4.6 \%$ at the expense of strength. Liang et al. ${ }^{[14]}$ discovered that the UTS and elongation reached 1,033-1,069 $\mathrm{MPa}$ and $12.2 \%-12.4 \%$ after heat treatment at $800{ }^{\circ} \mathrm{C}$ and $850{ }^{\circ} \mathrm{C}$ for $4 \mathrm{~h}$. Although good tensile performance may be obtained via post-processing treatments, the process chain " $\mathrm{AM}+$ postprocessing treatments" is time consuming and costly. Hence, EBM and SLM processes must be improved.

Optimizing the preheating process might be a good method to solve the aforementioned problems. Although it is likely to increase the overall building time, it can potentially reduce the lead time (compared with "AM+post-processing treatments"), improve the comprehensive properties, and broaden the process window. Ali et al. ${ }^{[15]}$ compared the effects of different powder bed preheating temperatures (370, 470, 570,670 and $770{ }^{\circ} \mathrm{C}$ ) used in SLM on the microstructure, residual stress, and mechanical properties of as-built Ti6Al4V. The preheating temperature of $570{ }^{\circ} \mathrm{C}$ was discovered to be the optimal temperature for manufacturing components with low residual stress $(1 \mathrm{MPa})$, high UTS $(1,223 \mathrm{MPa})$ and elongation (9.99\%). Leung et al. ${ }^{[16]}$ investigated the effects of preheating energy density on EBM Ti6Al4V by altering the scan repetitions. It was discovered that increasing the preheat energy density effectively increased the thermal conductivity of the powder bed and reduced its anisotropy but decreased its hardness and dimensional precision at the same time. Cao and Nash ${ }^{[17]}$ numerically investigated the effects of various preheating parameters, including preheating time, beam power, scan path, etc. The results showed that increasing the preheating time and energy input suppressed distortions and reduced residual stresses in EBM Ti6Al4V.

Currently, most studies have focused on conventional EBM and SLM, i.e., EBM at a high powder bed temperature (EBMHT) and SLM at a low powder bed temperature (SLM-LT). Although SLM at a high powder bed temperature (SLM-HT) has been achieved in non-commercial systems, few research works have focused on EBM at a low powder bed temperature (EBM-LT). Zhou et al. ${ }^{[18]}$ presented a novel electron beam and laser hybrid melting process, in which the interior and contour of Ti6Al4V were fabricated using electron beam and laser, respectively. The results showed that the hybrid process was superior to conventional EBM in terms of surface quality, confirming the significant potential of the electron beam and laser hybrid process. In this study, two kinds of electron beam and laser hybrid preheating (EB-LHP) strategies are proposed, i.e., "preheating via laser + melting via electron beam (EBMLT)" and "preheating via electron beam + melting via laser (SLM-HT)" by fully exploiting the zero risk of "smoke" in laser powder interactions and the high energy absorption rate of electron beam. The four types of manufacturing strategies, i.e., EBM-HT, EBM-LT, SLM-HT, and SLM-LT, were adopted to fabricate Ti6Al4V. The temperature-dependent surface features, microstructure, density, and mechanical properties of the as-built Ti6Al4V samples were analyzed and compared. 


\section{Material and methods}

The Ti6Al4V powder was fabricated via electrode inductionmelting and gas atomization. The chemical composition of the Ti6Al4V powder is listed in Table 1. The powder particles are spherical with small satellites attached to them. The particle size distribution ranges from 13 to $55 \mu \mathrm{m}$, with an average of $\sim 30 \mu \mathrm{m}$, determined using a laser particle size analyzer [Hydro 2000MU (A)]. The morphology and size distribution images of Ti6Al4V powder are available in Ref. [19].

Table 1: Chemical compositions of Ti6Al4V (wt.\%)

\begin{tabular}{cccccc} 
Al & V & C & N & O & Ti \\
\hline 6.05 & 3.94 & 0.02 & 0.02 & 0.087 & Bal.
\end{tabular}

Ti6Al4V samples were fabricated via EBM and SLM at high powder bed temperatures $\left(700-800{ }^{\circ} \mathrm{C}\right)$ and low powder bed temperatures $\left(100-200^{\circ} \mathrm{C}\right)$, as illustrated in Fig. 1. Figure 1(a) shows the EBM-HT process, i.e., a conventional EBM process at a high powder bed temperature. Figure 1(b) illustrates the EBM-LT process, in which the powder is directly preheated by laser instead of an electron beam, and subsequently selectively melted using an electron beam. Figure 1(c) shows the SLMHT process, in which substrate preheating and powder postpreheating using an electron beam are performed before and after conventional SLM, respectively. Powder post-preheating refers to that electron beam scans powder bed to maintain its temperature after laser selectively melts powder. Figure 1(d) shows the SLM-LT process, i.e., a conventional SLM process at a low powder bed temperature.

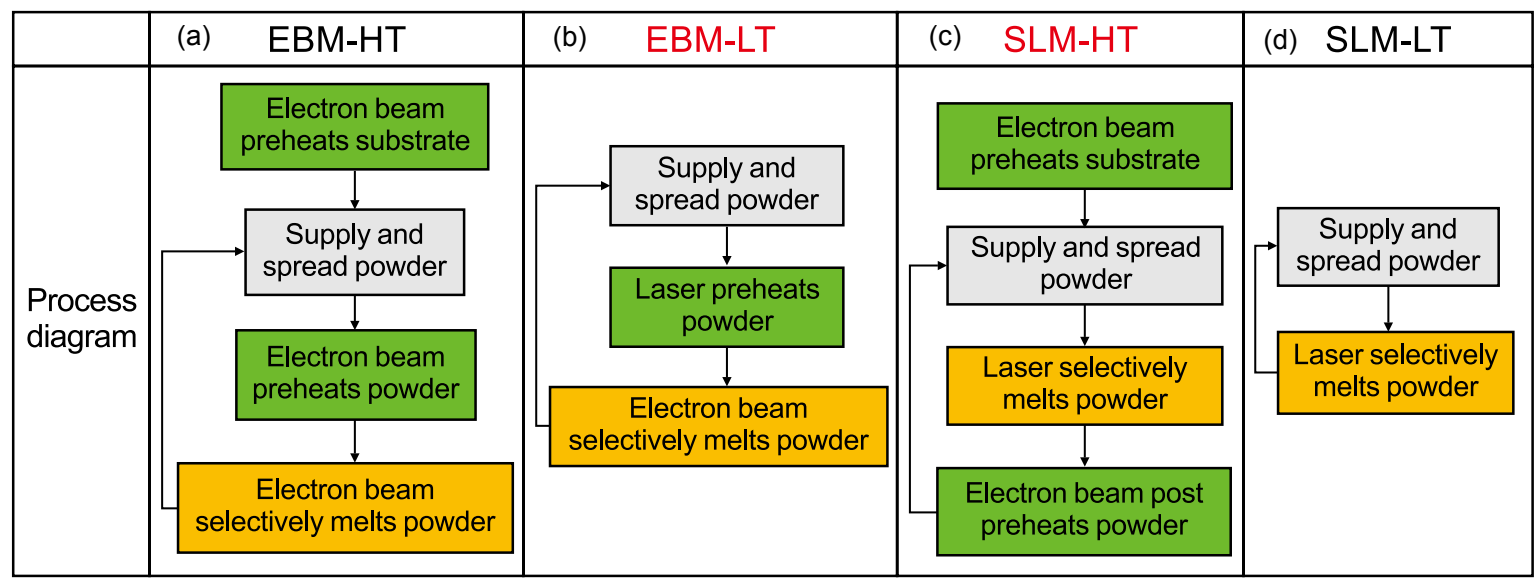

Fig. 1: Flow charts of four types of manufacturing strategies

The experiments were conducted using a self-developed EBLHP system ${ }^{[19]}$, which is an EBM device with an SLM device attached to the outside of the vacuum chamber. All experiments were performed under a vacuum of $1 \mathrm{~Pa}$. The substrates were made of Ti6Al4V with the size of $90 \mathrm{~mm} \times 90 \mathrm{~mm} \times 10 \mathrm{~mm}$. Cubic specimens of $20 \mathrm{~mm} \times 20 \mathrm{~mm} \times 10 \mathrm{~mm}$ were built with the layer thickness of $30 \mu \mathrm{m}$ and scan strategy of the zigzag pattern. The remaining experimental parameters are listed in Table 2. It is noteworthy that in this study, the laser must enter the vacuum chamber through a lens, which results in additional energy loss. Hence, the energy input or beam current in SLMHT and SLM-LT is higher than that in regular SLM. Zhou et al. ${ }^{[19]}$ reported that the formable energy input range of Ti6Al4V in

Table 2: Experimental parameters used in current study

$\begin{array}{ccc}\text { Parameters } & \text { EBM } & \text { SLM } \\ \text { Voltage }(\mathrm{kV}) & 60 & 60 \\ \text { Beam current }(\mathrm{mA}) & 3 & 2.5 \\ \text { Scan velocity }\left(\mathrm{mm} \cdot \mathrm{s}^{-1}\right) & 250 & 100 \\ \text { Line offset }(\mathrm{mm}) & 0.1 & 0.05\end{array}$

SLM under vacuum was $800-1,333 \mathrm{~J} \cdot \mathrm{mm}^{-3}$. Hence, the energy input during SLM was set to $1,000 \mathrm{~J} \cdot \mathrm{mm}^{-3}$. Three samples were fabricated for each condition for statistical analysis.

The surface morphology and roughness of the as-built specimens were analyzed using ZYGO Nexview with a vertical resolution of $0.1 \mathrm{~nm}$. The specimens for optical and SEM observation were ground and polished mechanically, and etched using a solution of $1 \mathrm{~mL} \mathrm{HNO}_{3}+2 \mathrm{~mL} \mathrm{HF}+97 \mathrm{~mL}+$ $\mathrm{H}_{2} \mathrm{O}$ for $10-15 \mathrm{~s}$. The microstructures of the horizontal crosssection perpendicular to the building direction were observed using optical microscopy (Olympus BX51M) and scanning electron microscopy (ZEISS-SUPRA55). The phase constitution was identified using X-ray diffraction (XRD). The chemical compositions of the powder and samples were measured using inductively coupled plasma and energy dispersive spectroscopy (EDS), respectively. The grains were characterized using electron backscattered diffraction (EBSD). The density of the samples was measured using a drainage method based on Archimedes' principle. Tensile tests at room temperature were performed on a WDW-100/E machine with a nominal displacement rate of $0.05 \mathrm{~mm} \cdot \mathrm{min}^{-1}$. The orientations and dimensions of the tensile specimens are shown in Fig. 2. The final tensile property values are the average of the six measurements. 


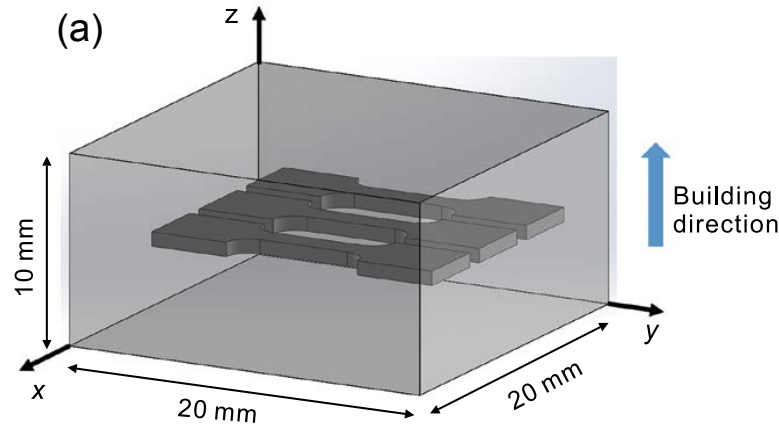

(b)

Fig. 2: Schematic illustrations of orientation (a) and dimensions (b) of tensile specimens

\section{Results and discussion}

\subsection{Surface features}

The fatigue life of the components is directly associated with their surface quality, thus machining is typically performed to improve their surface quality after AM. However, for components that are difficult to reprocess, such as porous components, the surface quality of the as-built components is critical ${ }^{[20]}$. Li et al. ${ }^{[21]}$ summarized the three main reasons contributing to surface roughness, i.e., staircase effect, semimolten powder particles sticking to the surface of solidified material, and defects such as porosity and lack of fusion which are sensitive to energy input. Figures 3 and 4 show the upper and side surface morphologies as well as the surface roughness of samples fabricated via four types of manufacturing strategies. Figures 3(a-d) show the openings and defects in different degrees on the upper surface of the samples formed using the four manufacturing strategies: flat surface [Fig. 3(a)], surface with small pores [Fig. 3(b)], and orange peel [Figs. 3(c) and (d)], indicating pore defects dominate the upper surface roughness. Among them, orange peel is the result of discontinuity of melted track due to the high scan velocity ${ }^{[22]}$. Figure 4 shows that the upper surface roughness by the four manufacturing strategies is similar, i.e., is approximately 4 $\mu \mathrm{m}$. Hence, it is concluded that a smooth upper surface can be obtained as long as appropriate process parameters are used whenever at elevated or low powder bed temperatures.

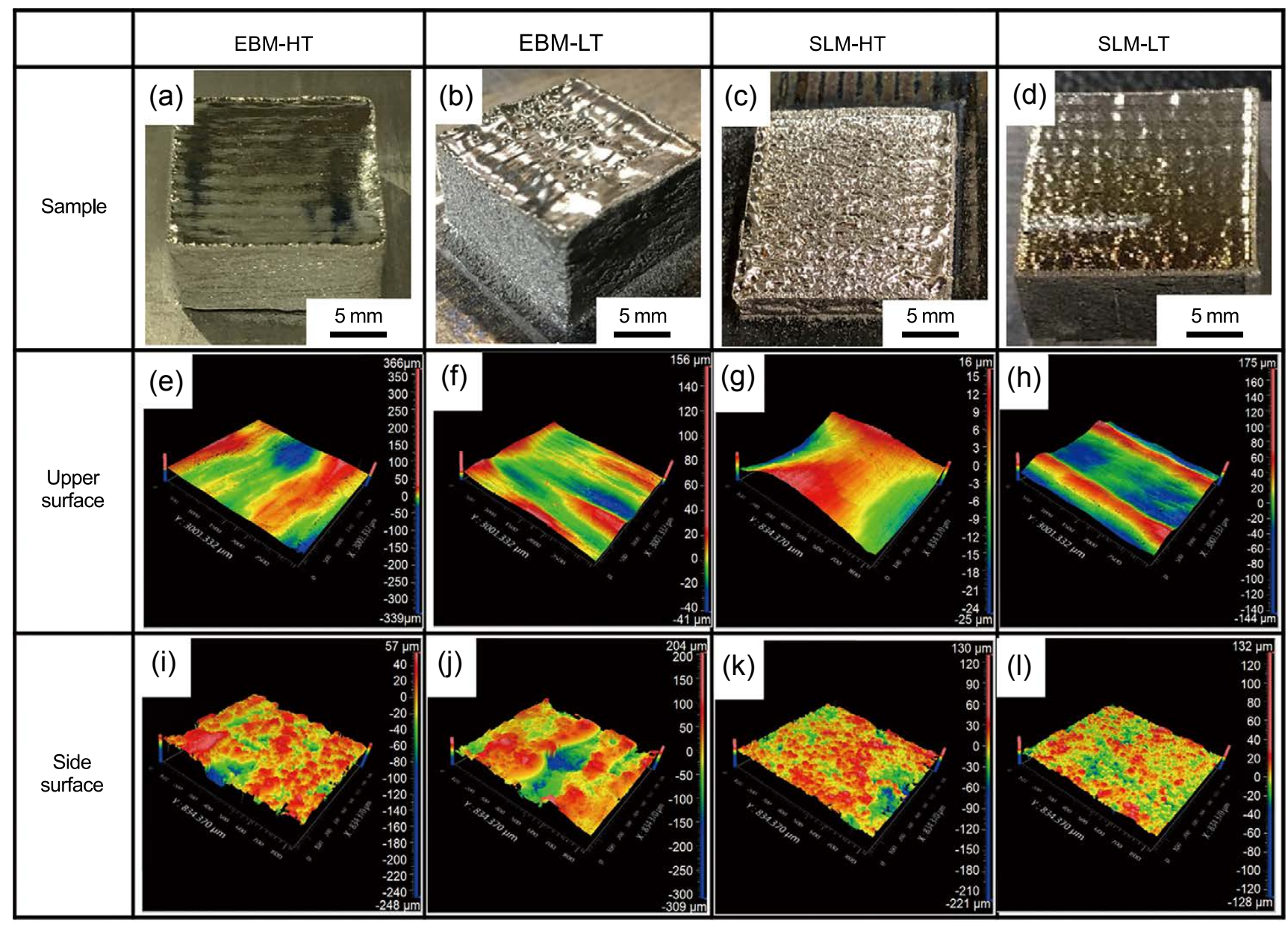

Fig. 3: Surface morphology of samples built by four types of manufacturing strategies 


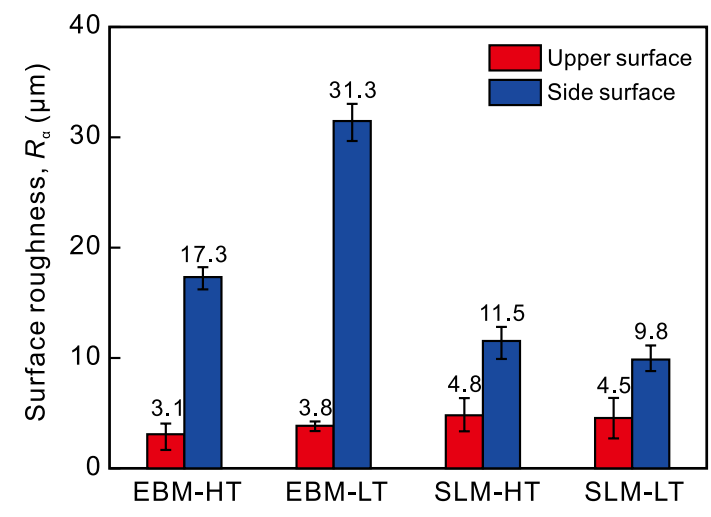

Fig. 4: Surface roughness of samples built by four types of manufacturing strategies

In contrast to the upper surfaces, the side surfaces of the samples are coarser in different degrees [Figs. 3(i)-3(1)]. This was because the surrounding molten powders inevitably adhered to the side of the formed component during EBM and SLM. Meanwhile this phenomenon is also associated closely with the staircase effect caused by the layer-wise features of AM technology. Assuming that the side edge of each layer is straight after melting and solidification of powders, the staircase effect on the side surface roughness can be simplified as ${ }^{[23]}$ :

$$
R_{\alpha}(\text { staircase })=(\text { Layer thickness } \times \cos \theta) / 4
$$

where $R_{\alpha}$ is the surface roughness caused by the staircase effect, and $\theta$ is the inclination angle of the side surface to the substrate. The larger the powder layer thickness and inclination angle of the samples, the greater the surface roughness caused by the staircase effect. In addition, at the same powder bed temperature, the side surfaces of the SLM samples are smoother than those of the EBM samples because of the smaller spot diameter and consequently higher precision (Fig. 4). Compared with EBM-HT and SLM-LT, samples by EBM-LT and SLM-HT show rougher side surface $(17.3 \mu \mathrm{m}$ vs. $31.3 \mu \mathrm{m}$, and $9.8 \mu \mathrm{m}$ vs. $11.5 \mu \mathrm{m}$, respectively). In other words, the side surfaces of the samples fabricated using the two EB-LHP strategies are coarser than those of the corresponding conventional EBM and SLM. This is a disadvantage of EB-LHP strategies, which may be caused by the significant temperature difference between the powder bed and formed components as well as the higher micro-sintering degree of the powder in the hybrid process. Nevertheless, it is noteworthy that SLM-HT remains advantageous in terms of surface quality compared with conventional EBM-HT (11.5 $\mu \mathrm{m}$ vs. $17.3 \mu \mathrm{m})$.

\subsection{Microstructure and density analysis}

Figure 5 shows the microstructures of the samples manufactured by EBM-HT and EBM-LT. The microstructure of the sample fabricated via EBM-HT shows a coarse Widmanstatten structure composed of $\alpha$ phase and a small amount of $\beta$ phase [Fig. 5(a)], which is a typical microstructure of conventional EBM. By contrast, the EBM-LT samples comprise $\alpha$ phase and acicular $\alpha^{\prime}$ martensite phase [Fig. 5(b)]. Liu and Shin ${ }^{[7]}$ summarized two conditions for $\alpha^{\prime}$ martensite formation, i.e., a building temperature below the martensite start temperature and a relatively high cooling rate. Ahmed and Rack ${ }^{[24]}$ discovered that martensite transformation occurred when the cooling rate reached $20^{\circ} \mathrm{C} \cdot \mathrm{s}^{-1}$ and completed when the cooling rate exceeded $410{ }^{\circ} \mathrm{C} \cdot \mathrm{s}^{-1}$. In the EBM-HT-manufactured Ti6Al4V, the cooling rate was $10^{3}-10^{5} \mathrm{~K} \cdot \mathrm{s}^{-1}{ }^{[25]}$. In contrast to EBM-HT, the cooling rate for EBM-LT is higher owing to the lower building temperature. Therefore, in the EBM-LT process, Ti6A14V underwent a complete martensite transformation. Then, the generated martensite $\alpha^{\prime}$ is incompletely decomposed to the $\alpha$ phase because of the insufficient building temperature $\left(<200{ }^{\circ} \mathrm{C}\right)$. This is consistent with the results reported by Gil et al. ${ }^{[26]}$, who discovered that the complete decomposition of $\alpha^{\prime}$ martensite occurred at high annealing temperatures $\left(>700^{\circ} \mathrm{C}\right)$, whereas the incomplete decomposition of $\alpha^{\prime}$ martensite occurred at low annealing temperatures $\left(<600^{\circ} \mathrm{C}\right)$.

Figure 6 shows the microstructures of the as-built samples manufactured by SLM-HT and SLM-LT. The $\alpha$ phase and regenerative $\beta$ phase are observed in the SLM-HT samples. This is because in SLM-HT, a high build temperature $\left(>700{ }^{\circ} \mathrm{C}\right)$ causes a complete decomposition of $\alpha^{\prime}$ martensite to the $\alpha+\beta$ dual-phase. For samples fabricated via conventional SLM, the $\alpha$ and $\alpha^{\prime}$ phases dominate the microstructures [Figs. $6(\mathrm{~b}, \mathrm{~d})$ ].
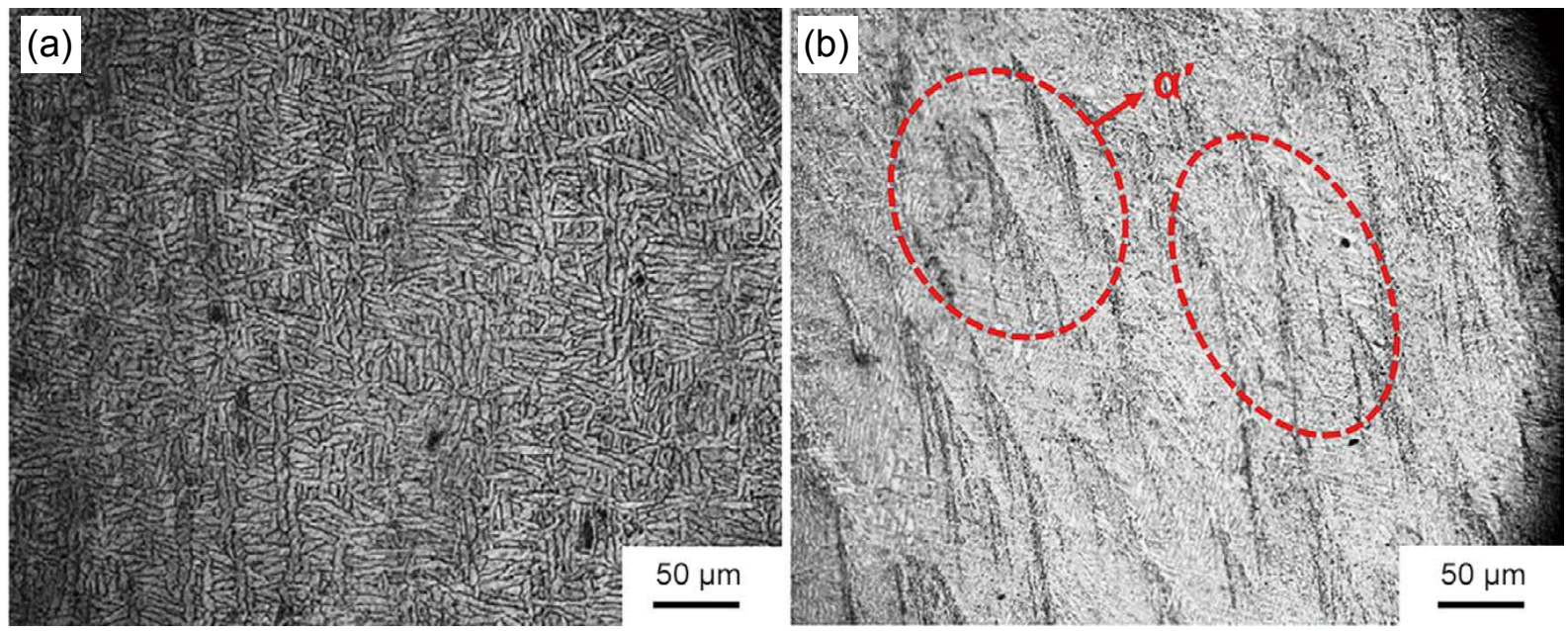

Fig. 5: Microstructures of as-built samples fabricated via EBM-HT (a) and EBM-LT (b) 

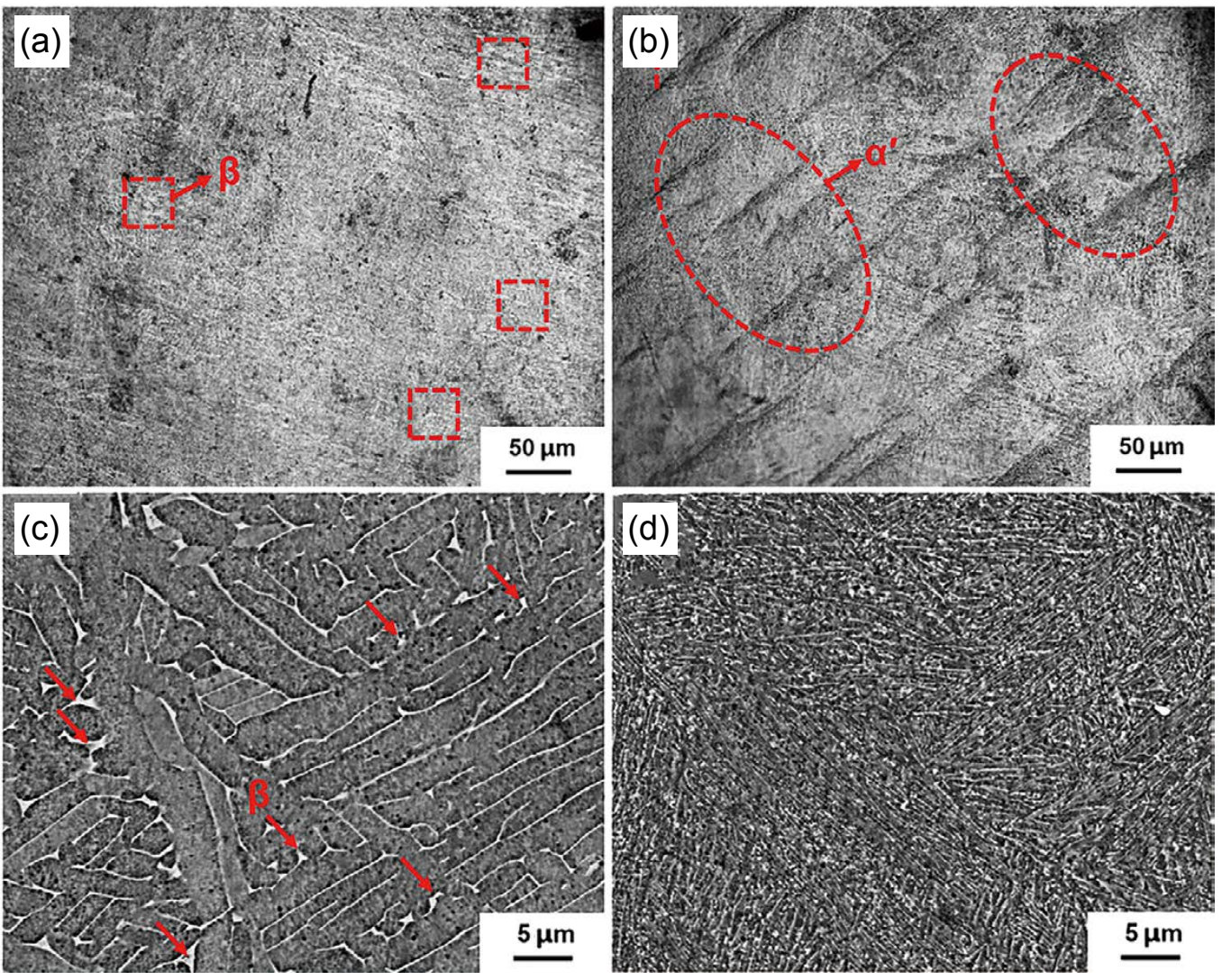

Fig. 6: Microstructures of as-built samples fabricated via SLM-HT (a), (c) and SLM-LT (b), (d)

Figure 7 shows the XRD spectra of the samples fabricated via four different manufacturing strategies. A number of $\alpha / \alpha^{\prime}$ peaks are observed in all the EBM and SLM samples. Furthermore, a small $\beta(100)$ peak is observed in the EBMHT and SLM-HT samples. Figure 8 shows the contents of elements in the original powder and as-built samples. It can be seen that Ti content does not change considerably. The Al content of samples fabricated at elevated temperatures is moderately higher than that at low temperatures, whereas the opposite is observed for the content of V. It is well-known that $\mathrm{Al}$ and $\mathrm{V}$ can stabilize the $\alpha$ and $\beta$ phases, respectively. Hence, the samples containing a higher content of $\mathrm{V}$ fabricated at low temperatures should have a larger fraction of $\beta$ phase compared with samples processed at elevated temperatures. This

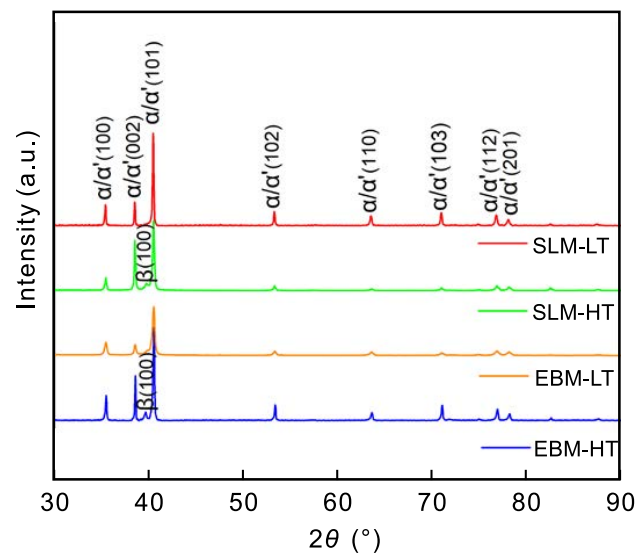

Fig. 7: XRD spectra of EBM and SLM samples built by four types of manufacturing strategies

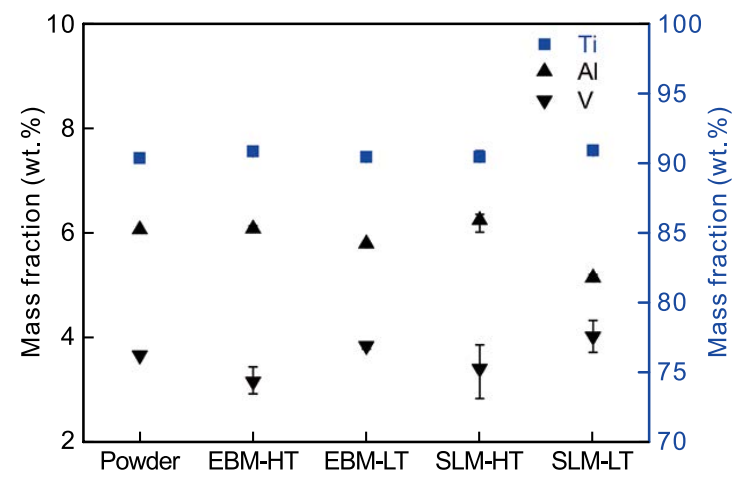

Fig. 8: Chemical composition of powder and samples built by four types of manufacturing strategies

inference is inconsistent with the experimental results (Fig. 7). Therefore, it is concluded that the slight variation in the chemical composition does not hinder the formation of martensite.

The grain orientation (Fig. 9) and grain size (Fig. 10) of the as-built samples were determined via EBSD. The grain sizes obtained at high temperatures are greater than those obtained at low temperatures in the corresponding process. This is reasonable because a higher temperature results in a faster grain growth and a larger grain size. It is noteworthy that the grain sizes obtained via SLM are smaller than those obtained via EBM, even at the same powder bed temperature (Fig. 10). The samples fabricated via SLM-LT exhibit the smallest grain size, $0.75 \mu \mathrm{m}$. This maybe because the electron beam has a higher energy absorption rate than the laser beam, resulting in a higher molten pool temperature and subsequent grain coarsening. 

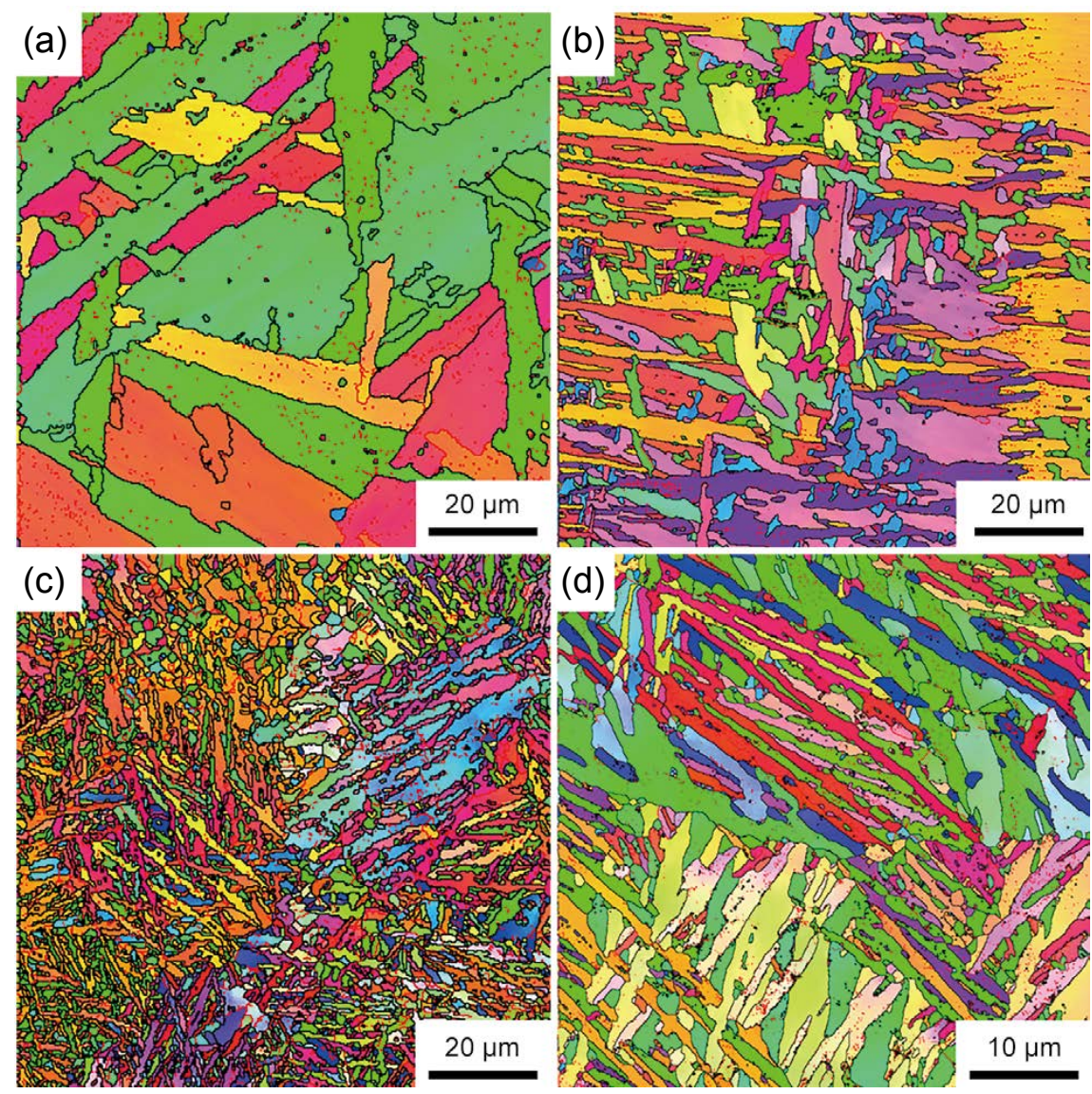

Fig. 9: EBSD of as-built samples fabricated by EBM-HT (a), EBM-LT (b), SLM-HT (c), and SLM-LT (d)

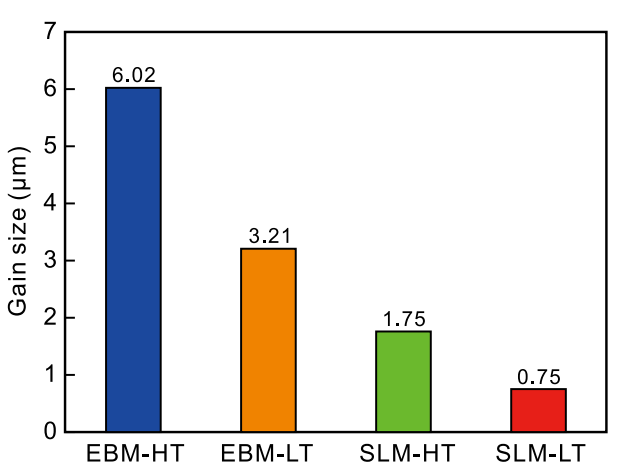

Fig. 10: Grain size of samples built by four types of manufacturing strategies

The density of the as-built samples significantly affects their mechanical properties. A comparison of the densities of the samples fabricated using the four types of manufacturing strategies is shown in Fig. 11. All of them exhibit high density. Among them, SLM-HT Ti6Al4V exhibits the highest density (99.92\%) based on the same melting parameters as conventional SLM, i.e., SLM-LT. EBM-LT Ti6Al4V possesses the lowest density $(97.61 \%)$. It is well-known that the density depends significantly on the process parameters; hence, the density of the EBM-LT samples can be improved by optimizing the process window. In addition, the density of samples fabricated at high temperatures is higher than those of samples fabricated at low temperatures because high temperatures favor the reduction of lack of fusion.

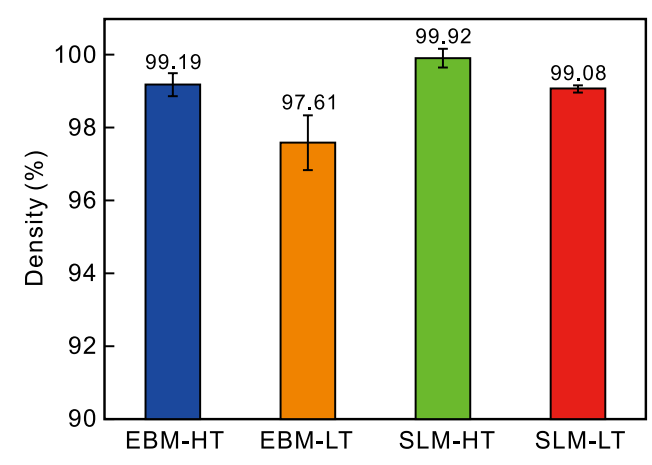

Fig. 11: Density of samples built by four types of manufacturing strategies

\subsection{Tensile properties}

The mechanical properties of the as-built samples are critical evaluation indexes that indicate whether novel EBLHP strategies can be utilized. One of the basic mechanical properties, i.e., tensile properties, were investigated. The stress-strain plots of the Ti6Al4V samples and the corresponding tensile results are shown in Fig. 12 and Table 3. It is well known that the mechanical properties of a material are significantly affected by its microstructures. The UTS of Ti6A14V exhibits the following trend: $\alpha^{\prime}$ martensite $>$ equiaxed $\alpha+\beta$ phase $>$ columnar $\alpha+\beta$ phase, whereas the ductility exhibits the opposite tendency ${ }^{[27]}$. Hence, owing to the presence of $\alpha^{\prime}$ martensite, the EBM-LT samples indicate a higher UTS $(981 \pm 43 \mathrm{MPa})$ and a lower 


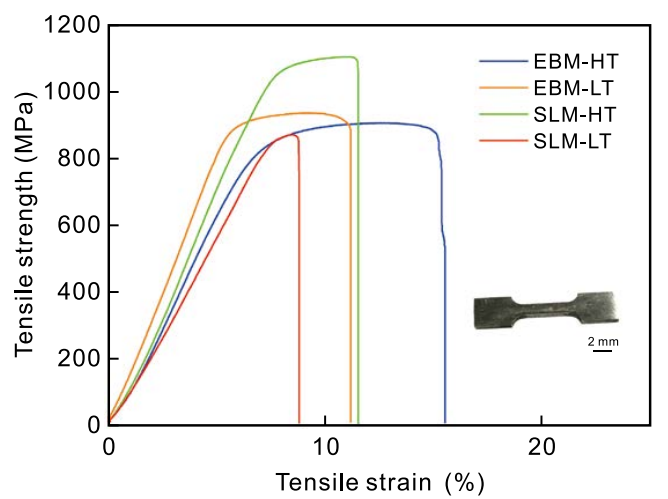

Fig. 12: Stress-strain curves of as-built Ti6Al4V samples

Table 3: Tensile results of as-built Ti6Al4V samples

\begin{tabular}{|ccc|}
\hline Samples & UTS $(\mathrm{MPa})$ & Strain $(\%)$ \\
\hline EBM-HT & $907 \pm 74$ & $16.6 \pm 1.2$ \\
EBM-LT & $981 \pm 43$ & $12.2 \pm 2.3$ \\
SLM-HT & $1,059 \pm 62$ & $14.8 \pm 4.0$ \\
SLM-LT & $935 \pm 65$ & $9.7 \pm 1.3$ \\
\hline
\end{tabular}
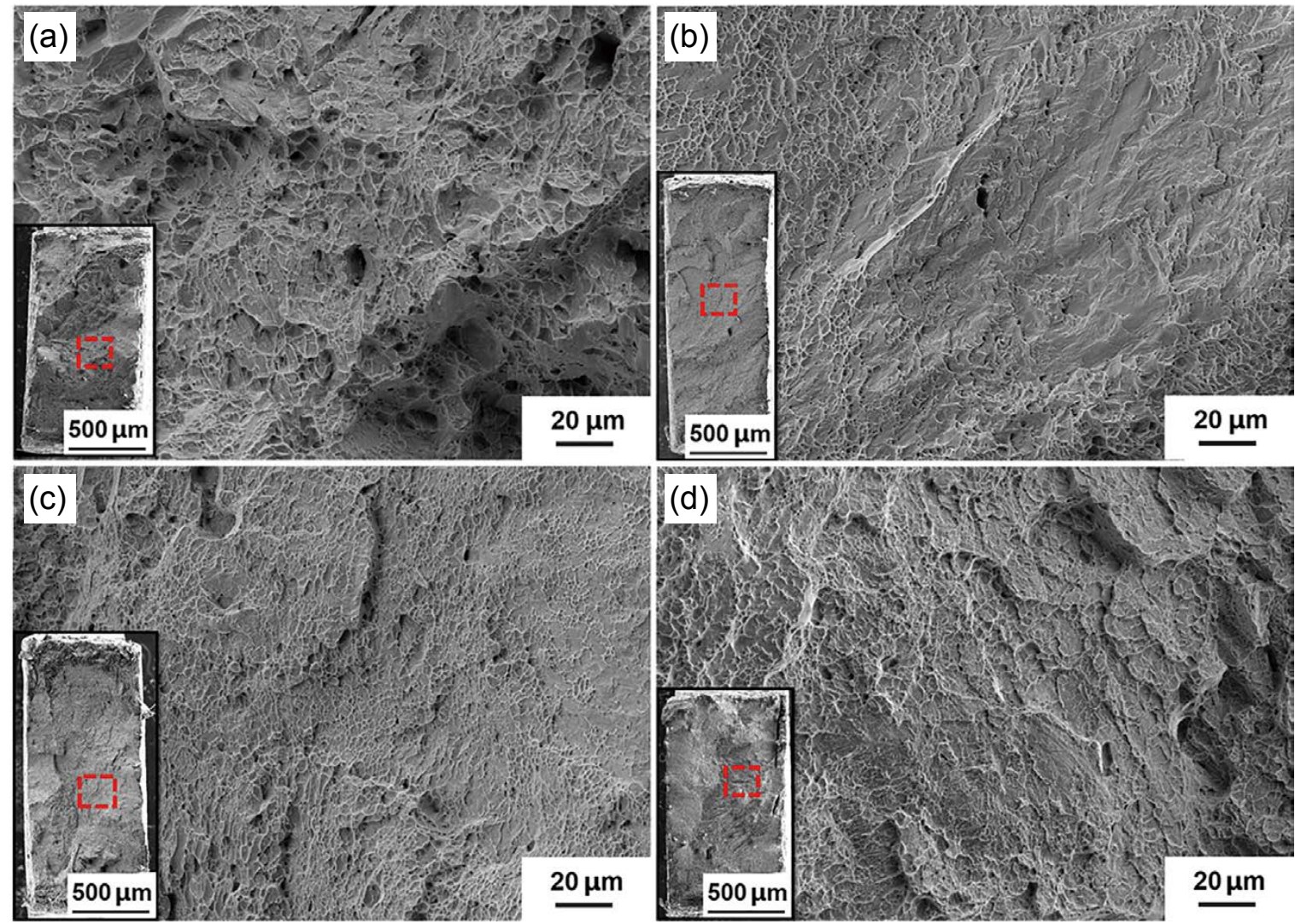

Fig. 13: Tensile fracture surface of as-built Ti6Al4V samples fabricated via EBM-HT (a), EBM-LT (b), SLM-HT (c), and SLM-LT (d)

\section{Conclusions}

Two novel EB-LHP strategies that widened the operating temperature ranges for EBM and SLM were presented. The surface features, microstructure, density, and mechanical properties of as-built Ti6Al4V fabricated via four different strain $(12.2 \% \pm 2.3 \%)$ than the conventional EBM samples. More notably, SLM-HT Ti6Al4V exhibits excellent tensile properties: its UTS $(1,059 \pm 62 \mathrm{MPa})$ is superior to that of SLMLT Ti6Al4V $(935 \pm 65 \mathrm{MPa})$, and the elongation $(14.8 \% \pm 4.0 \%)$ is comparable to that of EBM-HT Ti6Al4V $(16.6 \% \pm 1.2 \%)$. This is primarily attributed to the fine regenerative $\beta$ phase distributed in the lamellar $\alpha$ of the SLM-HT samples [Figs. 6(a) and (c)], thereby realizing dispersion strengthening. In addition, the favorable ductility of the $\beta$ phase contributes to the desirable tensile properties of the samples.

The fractographs of the tensile fracture surfaces of the as-built Ti6Al4V samples are shown in Fig. 13. The fracture surfaces of the EBM and SLM samples at elevated temperatures have numerous dimples, which are typical ductile features, as shown in Figs. 13(a) and (c). The fracture surfaces of the EBM and SLM samples at low temperatures are characterized by shallow ductile dimples and cleavage facets, indicating the ductile and brittle mixed fracture mechanism [Figs. 13(b) and (d)]. Hence, their ductility is relatively poor. In addition, the comparatively low density of EBM-LT Ti6A14V may contribute to its low ductility. manufacturing strategies (i.e., EBM-HT, EBM-LT, SLM-HT, and SLM-LT) were characterized and compared. The main conclusions are summarized as follows:

(1) The upper surface roughnesses of Ti6Al4V prepared by 
four manufacturing strategies with different bed temperatures are similar (approximately $4 \mu \mathrm{m}$ ). The SLM-HT Ti6Al4V exhibits a side surface roughness of $11.5 \mu \mathrm{m}$, comparable with SLM-LT Ti6Al4V $(9.8 \mu \mathrm{m})$. The EBM-LT Ti6Al4V has a maximum side surface roughness of $31.3 \mu \mathrm{m}$. The optimization strategy needs to be further investigated.

(2) Samples fabricated using conventional EBM and SLM are composed of $\alpha+\beta$ and $\alpha+\alpha^{\prime}$ phases, respectively. Nevertheless, EBM and SLM samples fabricated using the EB-LHP strategies are composed of $\alpha+\alpha^{\prime}$ and $\alpha+\beta$ phases, respectively, owing to the effects of the build temperature and cooling rate.

(3) The densities of the Ti6Al4V samples fabricated via EBM-HT, SLM-HT, and SLM-LT exceed 99\%. Based on the same melting parameters, SLM-HT can produce Ti6Al4V with a higher density (99.92\%) compared with SLM-LT (99.08\%).

(4) The EBM-LT samples possess a higher UTS ( $981 \pm 43 \mathrm{MPa})$ and a lower strain $(12.2 \% \pm 2.3 \%)$ compared with the conventional EBM samples owing to the presence of $\alpha^{\prime}$ martensite. Among the four samples, SLM-HT Ti6A14V exhibits the highest UTS $(1,059 \pm 62 \mathrm{MPa})$ and a ductility $(14.8 \% \pm 4.0 \%)$ comparable to that of EBM-HT Ti6Al4V $(16.6 \% \pm 1.2 \%)$.

\section{Acknowledgements}

This work was financially supported by the National Key R\&D Program (2018YFB1105200), 111 Project (B17026), and Open Fund of State Key Laboratory of Advanced Forming Technology and Equipment (SKL2019006).

\section{References}

[1] Rafi H K, Karthik N V, Gong H J, et al. Microstructures and mechanical properties of Ti6AI4V parts fabricated by selective laser melting and electron beam melting. J. Mater. Eng. Perform., 2013, 22(12): 3872-3883.

[2] Zhao X L, Li S J, Zhang M, et al. Comparison of the microstructures and mechanical properties of Ti-6Al-4V fabricated by selective laser melting and electron beam melting. Mater. Design, 2016, 95: 21-31.

[3] Chen W, Li Z Q. Additive manufacturing of titanium aluminides. In: Froes F, Boyer R (Eds.), Additive Manufacturing for the Aerospace Industry, Amsterdam: Elsevier Inc., 2019: 235-263.

[4] Cordero Z C, Meyer H M, Nandwana P, et al. Powder bed charging during electron-beam additive manufacturing. Acta Mater., 2017, 124: 437-445.

[5] Bartlett J L, Li X D. An overview of residual stresses in metal powder bed fusion. Addit. Manuf., 2019, 27: 131-149.

[6] Polmear I, StJohn D, Nie J F, et al. Light alloys, 5th Ed., Elsevier Ltd., 2017: 369-460.

[7] Liu S Y, Shin Y C. Additive manufacturing of Ti6Al4V alloy: A review. Mater. Design, 2019, 164, 107552.

[8] Vayssette B, Saintier N, Brugger C, et al. Surface roughness of Ti-6Al-4V parts obtained by SLM and EBM: Effect on the high cycle fatigue life. Procedia Eng., 2018, 213: 89-97.

[9] Haubrich J, Gussone J, Barriobero-Vila P, et al. The role of lattice defects, element partitioning and intrinsic heat effects on the microstructure in selective laser melted Ti-6Al-4V. Acta Mater., 2019, 167: 136-148.
[10] Liu J W, Sun Q D, Zhou C A, et al. Achieving Ti6Al4V alloys with both high strength and ductility via selective laser melting. Mat. Sci. Eng. A, 2019, 766:138319.

[11] Xu Y L, Zhang D Y, Guo Y W, et al. Microstructural tailoring of as-selective laser melted Ti6Al4V alloy for high mechanical properties. J. Alloy. Compd., 2020, 816: 152536.

[12] Gu D D, Hagedorn Y C, Meiners W, et al. Densification behavior, microstructure evolution, and wear performance of selective laser melting processed commercially pure titanium. Acta Mater., 2012, 60(9): 3849-3860.

[13] Liu C Y, Mai Z K, Yan D, et al. Effect of hot isostatic pressing on microstructures and mechanical properties of Ti6Al4V fabricated by electron beam melting. Metals, 2020, 10(5): 593.

[14] Liang Z L, Sun Z G, Zhang W S, et al. The effect of heat treatment on microstructure evolution and tensile properties of selective laser melted Ti6Al4V alloy. J. Alloy. Compd., 2019, 782: 1041-1048.

[15] Ali H, Ma L, Ghadbeigi H, et al. In-situ residual stress reduction, martensitic decomposition and mechanical properties enhancement through high temperature powder bed pre-heating of selective laser melted Ti6Al4V. Mat. Sci. Eng. A, 2017, 695: 211-220.

[16] Leung C L A, Tosi R, Muzangaza E, et al. Effect of preheating on the thermal, microstructural and mechanical properties of selective electron beam melted Ti-6Al-4V components. Mater. Des., 2019, 174, 107792.

[17] Cao J, Nash P. Numerical simulation of the effects of preheating on electron beam additive manufactured Ti-6Al-4V build plate. Mater. Sci. Forum, 2017, 879: 274-278.

[18] Zhou B, Zhou J, Li H X, et al. Fabrication and characterization of Ti6Al4V by selective electron beam and laser hybrid melting. In: Proceedings of the 28th Annual International-Solid Freeform Fabrication Symposium, 2017: 1924-1934.

[19] Zhou B, Zhou J, Li H X, et al. A study of the microstructures and mechanical properties of Ti6AI4V fabricated by SLM under vacuum. Mater. Sci. Eng. A, 2018, 724: 1-10.

[20] Fousova M, Vojtech D, Doubrava K, et al. Influence of inherent surface and internal defects on mechanical properties of additively manufactured Ti6Al4V alloy: Comparison between selective laser melting and electron beam melting. Materials, 2018, 11(4): 537.

[21] Li P, Warner D H, Fatemi A, et al. Critical assessment of the fatigue performance of additively manufactured Ti-6Al-4V and perspective for future research. Int. J. Fatigue, 2016, 85: 130-143.

[22] Kurzynowski T, Madeja M, Dziedzic R, et al. The effect of EBM process parameters on porosity and microstructure of Ti-5Al5Mo-5V-1Cr-1Fe alloy. Scanning, 2019: 2903920.

[23] Chen $Z$ E, Cao S, Wu X H, et al. Surface roughness and fatigue properties of selective laser melted Ti-6Al-4V alloy. In: Froes F, Boyer R (Eds.), Additive Manufacturing for the Aerospace Industry. Amsterdam: Elsevier Inc., 2019: 283-299.

[24] Ahmed T, Rack H J. Phase transformations during cooling in $\alpha+\beta$ titanium alloys. Mater. Sci. Eng. A, 1998, 243(1-2): 206-211.

[25] Al-Bermani S S, Blackmore M L, Zhang W, et al. The origin of microstructural diversity, texture, and mechanical properties in electron beam melted Ti-6Al-4V. Metall. Mater. Trans. A, 2010, 41(13): 3422-3434.

[26] Gil Mur F X, Rodríguez D, Planell J A. Influence of tempering temperature and time on the $\alpha^{\prime}-\mathrm{Ti}-6 \mathrm{Al}-4 \mathrm{~V}$ martensite. J. Alloy. Compd., 1996, 234(2): 287-289.

[27] Galarraga H, Warren R J, Lados D A, et al. Effects of heat treatments on microstructure and properties of Ti-6Al-4V ELI alloy fabricated by electron beam melting (EBM). Mater. Sci. Eng. A, 2017, 685: 417-428. 